\title{
EDITORIAL
}

\section{Progress in modelling acute lung injury in a pre-clinical mouse model}

\author{
Michael A. Matthay* and James P. Howard ${ }^{\#}$
}

4 nimal models of acute lung injury (ALI) have contributed significantly to our understanding of the pathogenesis and pathophysiology of the clinical syndrome of ALI and acute respiratory distress syndrome (ARDS) [1]. Investigators have used a wide variety of small- and largeanimal models in order to understand the mechanisms of injury to both the lung endothelial and epithelial barriers, as well as to test novel therapeutic strategies [2-4]. All animal models are limited in their ability to model the complex clinical syndrome of ALI/ARDS because they cannot replicate several of the confounding factors, including the effects of age, chronic medical diseases such as liver and renal insufficiency, and the impact of genetic and environmental factors that may contribute to the clinical syndrome of ALI/ARDS [3]. Nevertheless, animal models have made important contributions to understanding several of the mechanisms responsible for the development of lung injury $[4,5]$.

In this issue of the European Respiratory Journal, PATEL et al. [6] report a mouse model of ALI that reproduces several features of the pathophysiology of ALI. The authors used orotracheal instillation of hydrochloric acid to induce ALI, and then monitored the mice over 10 days to study both the development and the resolution of ALI. In the first 1-2 days, the mice demonstrated a decrease in oxygenation and lung compliance. They also developed protein-rich pulmonary oedema with acute lung inflammation, all characteristic features of ALI. The investigators used both bronchoalveolar (BAL) lavage and lung histology to quantify the degree of inflammation, including measurements of protein and pro-inflammatory cytokines in the airspaces. Furthermore, the authors measured in the BAL an important biochemical marker of alveolar epithelial injury, the receptor for advanced glycation end-products (RAGE) [7]. They found elevated levels of RAGE on days 1 and 2, which correlated with a decrease in alveolar fluid clearance on the same days. Measurement of alveolar fluid clearance (AFC) has not been routinely performed in small-animal ALI studies, but this measurement adds considerable insight into the function of the alveolar epithelium. This is also important because a decrease in AFC is characteristic of human ALI [8, 9]. There were also characteristic changes at each time-point, with an

*Dept of Medicine and Anesthesia, and the Cardiovascular Research Institute and "Dept of Pediatrics, University of California, San Francisco, CA, USA.

CORRESPONDENCE: M.A. Matthay, Cardiovascular Research Institute, University of California, San Francisco, 505 Parnassus Ave, M-917, Box 0624, San Francisco, CA 94143-0624, USA. E-mail: michael.matthay@ucsf.edu early acute neutrophil infiltration and a later predominance of macrophages. The authors found a marked decrease in oxygenation over the first $24 \mathrm{~h}$ (as measured by the arterial oxygen tension/inspiratory oxygen fraction ratio) with a gradual recovery over the next 5-10 days. Similarly, to quantify the degree of pulmonary oedema, the authors measured an increase in the mean wet-to-dry ratio of the lungs to a peak level of $7.2 \mathrm{~g}$ $\mathrm{H}_{2} \mathrm{O}$ per gram of dry lung that declined to a near-normal level of $4.8 \mathrm{~g} \mathrm{H}_{2} \mathrm{O}$ per gram of dry lung by day 3 . These findings were matched by a marked increase in BAL neutrophils over 2 days, with a modest increase in mononuclear cells. Interestingly, BAL lymphocytes increased at day 10 , supporting a possible role in resolution of lung injury by lymphocytes [10]. There was a marked increase in pro-inflammatory cytokines at days 1 and 2, and a gradual decline thereafter. While there was a surge and decline of several indicators of lung injury, the mean values were only significantly different from baseline. It may be that analysis of a greater number of animals reveals significant point-to-point trends, it is also possible that later points will only vary from the initial control, potentially limiting the utility of the model for demonstrating significant differences in ALI biomarkers. That said, the initial data suggest that this model will be valuable in assessing the nature of itinerant cells and transient factors that are important for both the evolution and the resolution of ALI.

There have been two recent reports that discussed animal models of ALI; first, a fine review by MATUTE-BELLO et al. [2], in which the authors described several models of ALI, including endotoxin, live bacteria and acid instillation. Secondly, a recent American Thoracic Society article provided guidelines for what investigators must consider measuring in all pre-clinical models of ALI [5]. The current report by PATEL et al. [6] encompassed virtually all of the recommended measurements. Although large-animal models are more challenging, sheep studies can be especially valuable because they can be studied over $24 \mathrm{~h}$ and lung lymph flow can be measured as an indicator of lung endothelial injury. Also, alveolar epithelial fluid clearance can be measured. However, one superior feature of this murine model is the potential to combine the approach with everexpanding engineered genetic backgrounds not available in other animal models of ALI.

In summary, the report by PATEL et al. [6] provides an excellent, comprehensive model of ALI in mice that should be of substantial value to investigators in the field. The authors have done an outstanding job of modelling lung injury in terms of the early and later phases, including injury to the lung endothelium and the alveolar epithelium, with physiological, biochemical 
and histological measures of both the development of lung injury and the resolution phase. It will be valuable if this model can be adapted to studies of bacterial and viral infection in the lung as well, given the predominance of these aetiologies in human ALI.

\section{SUPPORT STATEMENT}

This editorial was supported by National Heart Lung and Blood Institute grants HL51856 and HL51854 to M.A. Matthay and an NIH Pediatric Scientist Development Program Award to J.P. Howard.

\section{STATEMENT OF INTEREST}

None declared.

\section{REFERENCES}

1 Ware LB, Matthay MA. The acute respiratory distress syndrome. N Engl J Med 2000; 342: 1334-1349.

2 Matute-Bello G, Frevert CW, Martin TR. Animal models of acute lung injury. Am J Physiol Lung Cell Mol Physiol 2008; 295: L379-L399.

3 Ware LB. Modeling human lung disease in animals. Am J Physiol Lung Cell Mol Physiol 2008; 294: L149-L150.
4 Bastarache JA, Blackwell TS. Development of animal models for the acute respiratory distress syndrome. Dis Model Mech 2009; 2 218-223.

5 Matute-Bello G, Downey G, Moore BB, et al. An official American Thoracic Society workshop report: features and measurements of experimental acute lung injury in animals. Am J Respir Cell Mol Biol 2011; 44: 725-738.

6 Patel BV, Wilson MR, Takata M. Resolution of acute lung injury and inflammation: a translational mouse model. Eur Respir J 2012; 39: $1162-1170$.

7 Calfee CS, Ware LB, Eisner MD, et al. Plasma receptor for advanced glycation end products and clinical outcomes in acute lung injury. Thorax 2008; 63: 1083-1089.

8 Matthay MA, Wiener-Kronish JP. Intact epithelial barrier function is critical for the resolution of alveolar edema in humans. Am Rev Respir Dis 1990; 142: 1250-1257.

9 Ware LB, Matthay MA. Alveolar fluid clearance is impaired in the majority of patients with acute lung injury and the acute respiratory distress syndrome. Am J Respir Crit Care Med 2001; 163: 1376-1383.

$10 \mathrm{D}^{\prime}$ Alessio FR, Tsushima K, Aggarwal NR, et al. CD4 ${ }^{+} \mathrm{CD} 25^{+} \mathrm{Foxp} 3^{+}$ Tregs resolve experimental lung injury in mice and are present in humans with acute lung injury. J Clin Invest 2009; 119: 2898-2913. 